\title{
Evaluating the Current Place of Radiotherapy as Treatment Option for Patients With Muscle Invasive Bladder Cancer in Belgium
}

\author{
Valérie Fonteyne, ${ }^{1}$ Elke Rammant, ${ }^{1}$ Piet Ost, ${ }^{1}$ Yolande Lievens, ${ }^{1}$ Bart De Troyer, ${ }^{3}$ \\ Sylvie Rottey, ${ }^{4}$ Gert De Meerleer, ${ }^{2}$ Daan De Maeseneer, ${ }^{4}$ Dirk De Ridder, ${ }^{5}$ \\ Karel Decaestecker ${ }^{6}$
}

\section{Abstract}

\begin{abstract}
Radiotherapy is a potent player in the treatment of different stages of bladder cancer. Although the place of radiotherapy is recognized by international guidelines, an underusage of radiotherapy in bladder cancer is confirmed in this Belgian survey. Awareness about the place of radiotherapy in bladder cancer must be increased.

Introduction: There is a gap between optimal and actual use of radiotherapy (RT) in muscle-invasive bladder cancer (MIBC). We investigated the opinions of radiation-oncologists, urologists, and medical oncologists on use of RT in different cases. Barriers and facilitators for applying guidelines were examined. Material and Methods: A web-based survey was developed at Ghent University Hospital and conducted from November 18, 2016 to July 17, 2017. The place of primary, adjuvant, and palliative RT was evaluated. Additional questions assessed the use of guidelines, barriers, and facilitators. Results: In total, 126 physicians (57 radiation oncologists, 41 urologists, and 28 medical oncologists) completed the survey. Significant differences in use of RT in the primary and adjuvant setting were observed between radiation oncologists and urologists. Younger age and presence of hydronephrosis are perceived as contraindications for RT in the primary setting. In the adjuvant setting, RT was mainly considered in case of positive surgical margins. All radiation oncologists and $96 \%$ of medical oncologists considered palliative RT for patients with painful bone metastases, whereas $21 \%$ of urologists did not $(P<.001)$. Clinical decisions are mainly based on EAU guidelines. The most important reason for nonadherence to guidelines is external barriers (18\%). One strategy to improve awareness of guidelines is a summary of guidelines on the website of national organizations $(54 \%)$. Conclusion: There is controversy regarding the place of RT in MIBC, with a clear variation between professionals. Barriers and facilitators to use RT should be addressed, seeing the gap in RT utilization and predicted increase in patients requiring RT for MIBC.
\end{abstract}

Clinical Genitourinary Cancer, Vol. m, No. m, 1-9 ๑ 2018 Elsevier Inc. All rights reserved.

Keywords: Awareness, Radiation, Survey, Underusage, Urothelial carcinoma

\section{Introduction}

A radical cystectomy $(\mathrm{RC})$ is generally considered to be the golden standard for patients with muscle-invasive bladder cancer (MIBC). Depending on tumor characteristics and staging and whether or not neoadjuvant chemotherapy has been administrated, adjuvant

\footnotetext{
${ }^{1}$ Department of Radiation Oncology and Experimental Cancer Research, Ghent University, Ghent, Belgium

${ }^{2}$ Department of Radiation Oncology, University Hospitals Leuven, Belgium

${ }^{3}$ Department of Urology, AZ Nikolaas, Sint Niklaas, Belgium

${ }^{4}$ Department of Medical Oncology, Ghent University Hospital, Ghent, Belgium

${ }^{5}$ Department Development and Regeneration, Organ Systems, Urology, University

Hospitals Leuven, Leuven, Belgium

${ }^{6}$ Department of Urology, Ghent University Hospital, Ghent, Belgium
}

chemotherapy is a treatment option, although no level 1 evidence exists for this approach. ${ }^{1}$ In the metastatic setting, palliative chemotherapy and, more recently, immunotherapy are available to prolong survival. Immunotherapy is currently also tested as adjuvant treatment in clinical trials, but conclusions are not yet mature.

Submitted: Mar 28, 2018; Revised: Jun 7, 2018; Accepted: Jul 27, 2018

Address for correspondence: Dr Valérie Fonteyne, UZ Ghent, Radiotherapy Oncology, De Pintelaan 185, 9000 Ghent, Belgium

E-mail contact: Valerie.fonteyne@uzgent.be 


\section{The Current Place of Radiotherapy in Muscle Invasive Bladder Cancer}

Another important therapy for patients with bladder cancer is radiotherapy (RT). Evidence-based decision algorithms estimate that about 1 of 2 patients with cancer diagnosed with bladder cancer will require RT during the course of their disease. ${ }^{2}$ Equally important is that by 2025 the need for RT for bladder cancer is predicted to increase by $21 \%$, which would translate in bladder cancer ranking among the top 5 indications for radiotherapy in several European countries, among which is Belgium. ${ }^{3}$ Unfortunately, in spite of this evidence and despite international guidelines recommending RT at different stages of the disease, the actual utilization of RT for bladder cancer remains limited. In Belgium, for instance, only $18 \%$ of patients diagnosed with bladder cancer in 2009 to 2010 actually received RT, compared with the optimal of $47 \%$ computed for this specific patient population. ${ }^{4}$

This indicates that nowadays the majority of patients with MIBC who would benefit from RT are denied an effective treatment, with an important gap between the optimal and actual use of RT. Factors affecting optimal utilization of evidence-based treatment strategies, hence the adherence to clinical guidelines, are typically multifactorial. They may be embedded within the healthcare system itself (eg, lack of resources or inappropriate financial incentives), the practice environment (eg, incorrect referral patterns), the educational environment (eg, inadequate continuing medical education), the social environment (eg, inappropriate demands and/or beliefs created by the influence of the media), or the political environment (eg, dominance of short-term thinking in supporting cancer plans). Lastly, the introduction and implementation of optimal care will ultimately be driven by the interaction between practitioners and patients, who may have different demands or incentives towards a certain treatment strategy. 5,6

Little is known about the adherence to clinical guidelines in the setting of MIBC and about the incentives driving treatment decision. Therefore, we initiated this survey in which we assess: (1) the perceptions of urologists, radiation oncologists and medical oncologists on the place of RT in MIBC at different stages and (2) possible barriers for the application of clinical practice guidelines on $\mathrm{RT}$ in MIBC and define possible facilitators.

\section{Materials and Methods}

\section{Study Design, Participants, and Procedure}

A web-based survey (aiming at radiation oncologists, urologists, and medical oncologists) was developed and pilot-tested at the Ghent University Hospital. Eligible participants were Belgian urologists, radiation oncologists, and medical oncologists. The survey was disseminated through the Belgian Association of Urology, Belgian College for Physicians in Radiation Oncology, and Belgian Society of Medical Oncologists, respectively. The survey was conducted from November 18, 2016 to July 17, 2017.

\section{Survey Content}

The survey consisted of 10 questions, divided into 3 separate sections. The first section consisted of general information to identify the characteristics of the respondents (type of hospital, clinical experience, and specialty). The second part included different cases to define the place of primary, adjuvant, and palliative RT in patients with MIBC. The third part consisted of closedended questions on the use of guidelines, possible barriers, and facilitators for using RT in MIBC. The complete survey can be found in the Supplemental Table 1 (in the online version).

\section{Statistical Analyses}

The $\chi^{2}$ and Fisher exact test were applied to compare the answers of the different participants per specialty. A $P$-value $<.05$ was considered significant. Statistical analysis was performed using Statistical Package for the Social Sciences (SPSS, Chicago, IL) version 25.0 .

\section{Guidelines}

The following guidelines were consulted to summarize current recommendations concerning the place of RT in MIBC: European Association of Urology (EAU), ${ }^{7}$ National Comprehensive Cancer Network (NCCN), ${ }^{8}$ European Society of Medical Oncology (ESMO), and American Urological Association/American Society of Clinical Oncology/American Society of Radiation Oncology/ Society of Urologic Oncology (AUA/ASCO/ASTRO/SUO). ${ }^{10}$ An overview of the existing EAU, NCCN, ESMO, and AUA/ASCO/ ASTRO/SUO guidelines and recommendations on use of RT in patients with MIBC is presented in Table $1 .^{7-10}$

\section{Results}

\section{Study Participants}

The survey was send to 233 urologists, 231 radiation oncologists, and 240 medical oncologists. The overall response rate was $18 \%$ and $18 \%, 25 \%$, and $12 \%$ for urologists, radiation oncologists, and medical oncologists, respectively. Finally 126 participants filled in the survey, of whom 41 (33\%) were urologists, 57 (45\%) were radiation oncologists, and $28(22 \%)$ were medical oncologists. The majority of the participants were active in a nonacademic hospital (71\%) and had more than 10 years of experience (67\%), without significant differences between specialties. Respectively, $12 \%$ and $21 \%$ of the participants had $<5$ years and 5 to 10 years of experience. This was again equally distributed between specialties.

\section{Clinical Cases: Place of Radiotherapy in MIBC in the Primary Setting}

One hundred twenty-two (97\%) participants filled in the questions on 'place of RT in the primary setting:' 40 (98\%) urologists, $55(96 \%)$ radiation oncologists, and $27(96 \%)$ medical oncologists.

Figure 1 represents the percentages of all participants and per discipline separately considering RT in the primary setting per case, for 3 different scenarios.

In elderly patients, significantly more urologists would not offer RT as primary treatment compared with radiation oncologists (case 1: 'no' answered by urologists in 30\% vs. radiation oncologists in $9 \% ; P=.012$ ).

In younger patients (case 2), reluctance toward RT increases as more than $50 \%$ of urologists and medical oncologists would not consider offering RT as primary treatment (case 2: 'no' answered by urologists in $78 \%$ and medical oncologists in $70 \%$ vs. radiation oncologists in $31 \% ; P<.001)$. Also, the presence of hydronephrosis was considered to be a contraindication for primary RT by the majority of participants (case 3: 'no' answered by urologists in $83 \%$ and medical oncologists in $74 \%$ vs. radiation oncologists in $53 \% ; P=.03)$. 
Table 1 Overview of Existing Guidelines on Place of radiotherapy in Muscle Invasive Bladder Gancer According to the EAU, NCCN, ESMO, and AUA/ASCO/ASTRO/SUO

\begin{tabular}{|c|c|c|c|c|}
\hline \multicolumn{5}{|c|}{ Primary Radiotherapy } \\
\hline \multirow{2}{*}{$\begin{array}{l}\text { Guidelines } \\
\text { EAU }\end{array}$} & $\begin{array}{l}\text { Patient 1: Age } 80 \text { Years; } \\
\text { pT2 cNO cM0; Grade } 3 \text { TCC; } \\
\text { No Hydronephrosis; } \\
\text { No Comorbidities }\end{array}$ & $\begin{array}{l}\text { Patient 2: Same as Patient } 1 \\
\text { Except for Age } 70 \text { years }\end{array}$ & $\begin{array}{l}\text { Patient 3: Same as Patient } 1 \\
\text { Except for Hydronephrosis }\end{array}$ & $\begin{array}{l}\text { Evidence/ } \\
\text { Recommendation }\end{array}$ \\
\hline & \multicolumn{3}{|c|}{$\begin{array}{c}\text { In a highly selected patient population, long-term survival rates of multimodality treatment are comparable to those of } \\
\text { early cystectomy }\end{array}$} & LE: $2 b$ \\
\hline & \multicolumn{3}{|c|}{ In patients aged $>80$ years with MIBC, cystectomy is an option } & LE: 3 \\
\hline & \multicolumn{3}{|c|}{$\begin{array}{l}\text { Offer multimodality treatment as an alternative in selected, well-informed, and compliant patients, especially for whom } \\
\text { cystectomy is not an option }\end{array}$} & GR: B \\
\hline & Offer radi & ystectomy in T2-T4a, NOM0, and high & non-MIBC & GR: A \\
\hline \multirow[t]{2}{*}{ NCCN } & \multicolumn{3}{|c|}{ Offer multimodality treatment (concurrent radiochemotherapy after TURB) as an alternative for radical cystectomy } & LE: $2 A$ \\
\hline & \multicolumn{3}{|c|}{ For non-cystectomy candidates, offer concurrent radiochemotherapy or RT or TURB alone } & \\
\hline \multirow[t]{3}{*}{ ESMO } & \multicolumn{3}{|c|}{$\begin{array}{l}\text { Concurrent chemoradiotherapy or RT alone is most successful for patients without hydronephrosis } \\
\text { and without extensive carcinoma in situ }\end{array}$} & $\| I, B$ \\
\hline & \multicolumn{3}{|c|}{$\begin{array}{l}\text { The approach of organ preservation therapy for MIBC is a reasonable option for patients seeking an alternative to } \\
\text { cystectomy and a palliative option for those who are medically unfit for surgery. The preferred treatment is a tri-modality } \\
\text { combination of TURB plus RT and chemotherapy }\end{array}$} & \\
\hline & \multicolumn{3}{|c|}{$\begin{array}{l}\text { Criteria determining whether patients are ideal candidates for bladder preservation are: early tumor stage (including } \\
\text { high-risk T1 disease, T2 }<5 \mathrm{~cm} \text { ), visibly complete TURB, absence of associated CIS and ureteral obstruction, and } \\
\text { adequate bladder capacity and function }\end{array}$} & \\
\hline $\begin{array}{l}\text { AUA/ASCO/ } \\
\text { ASTRO/SUO }\end{array}$ & \multicolumn{3}{|c|}{$\begin{array}{c}\text { For patients with newly diagnosed non-metastatic MIBC who desire to retain their bladder and for those with significant } \\
\text { comorbidities for whom radical cystectomy is not a treatment option, clinicians should offer bladder preserving therapy } \\
\text { when clinically appropriate }\end{array}$} & GR: C \\
\hline \multicolumn{5}{|c|}{ Adjuvant Radiotherapy } \\
\hline & $\begin{array}{l}\text { Patient 1: Age } 65 \text { Years; } \\
\text { pT3b pNO cM0; R1; } \\
\text { Neoadjuvant chemotherapy; } \\
\text { No neobladder }\end{array}$ & $\begin{array}{l}\text { Patient 2: Same as Patient } 1 \\
\text { Except for With Neobladder }\end{array}$ & $\begin{array}{l}\text { Patient 3: Same as Patient } 1 \\
\text { Except for Tumor Stage } \\
\text { pT3a pN2 (2/12) cM0; R0 }\end{array}$ & $\begin{array}{l}\text { Evidence/ } \\
\text { Recommendation }\end{array}$ \\
\hline \multirow[t]{2}{*}{ EAU } & \multicolumn{3}{|c|}{$\begin{array}{c}\text { There are only very limited, old data on adjuvant RT after RC. Advances in targeting and reducing the damage to surrounding } \\
\text { tissue may yield better results in the future. In locally advanced BC (T3-T4, NO/N1, MO) the local recurrence rate seems } \\
\text { to decrease with postoperative RT. }\end{array}$} & NA \\
\hline & \multicolumn{3}{|c|}{$\begin{array}{l}\text { Offer adjuvant ciplatin-based combination chemotherapy to patients with } \mathrm{pT} / 4 \text { and/or } \mathrm{pN}+\text { disease if no neoadjuvant } \\
\text { chemotherapy has been given }\end{array}$} & GR: B \\
\hline NCCN & \multicolumn{3}{|c|}{$\begin{array}{c}\text { Based on pathologic risk factors (pT3-4, positive nodes, positive margin or high-grade): consider adjuvant RT, or if no } \\
\text { neoadjuvant treatment was given, chemotherapy }\end{array}$} & LE: $2 A$ \\
\hline ESMO & \multicolumn{3}{|c|}{$\begin{array}{l}\text { Although there is still insufficient evidence for the routine use of adjuvant chemotherapy in clinical practice (I,A), } \\
\text { it is likely that high-risk patients (extravesical and/or node-positive disease) that have not received neoadjuvant } \\
\text { chemotherapy will benefit most from adjuvant chemotherapy. }\end{array}$} & NA \\
\hline $\begin{array}{l}\text { AUAVASCO/ } \\
\text { ASTRO/SUO }\end{array}$ & \multicolumn{3}{|c|}{$\begin{array}{l}\text { Eligible patients who have not received cisplatin-based neoadjuvant chemotherapy and have non-organ confined } \\
\text { (pT3/T4 and/or N) disease at cystectomy should be offered adjuvant cisplatin-based chemotherapy }\end{array}$} & GR: C \\
\hline
\end{tabular}




\section{The Current Place of Radiotherapy in Muscle Invasive Bladder Cancer}

\begin{tabular}{|c|c|c|c|}
\hline \multicolumn{4}{|c|}{ Radiotherapy in the Metastatic Setting } \\
\hline & $\begin{array}{l}\text { Patient 1: Age } 75 \text { years; pT4 pN1 cM1; } \\
\text { Visceral Metastases; } 1 \text { Painful Bone Metastasis }\end{array}$ & $\begin{array}{l}\text { Patient 2: Same as Patient } 1 \text { Except for } \\
\text { No Painful Bone Lesions; Lymph Node } \\
\text { Recurrence in the Right Obturator Region } \\
\text { With Pain Radiating to the Right Leg }\end{array}$ & $\begin{array}{c}\text { Evidence/ } \\
\text { Recommendation }\end{array}$ \\
\hline EAU & & $\begin{array}{c}\text { Cisplatin-containing combination chemotherapy can achieve } \\
\text { median survival of up to } 14 \text { months, with long-term } \\
\text { disease-free survival reported in } \approx 15 \% \text { of patients with nodal } \\
\text { disease and good PS }\end{array}$ & GR: $1 b$ \\
\hline NCCN & Systemic therapy or RT & $\begin{array}{c}\text { Systemic therapy or chemoradiotherapy } \\
\text { (if no previous RT) or RT }\end{array}$ & LE: $2 A$ \\
\hline \multirow[t]{2}{*}{ ESMO } & $\begin{array}{l}\text { Cisplatin-containing combination chemotherapy with GC or } \\
\text { MVAC is standard in advanced surgically unresectable and } \\
\text { metastatic patients fit enough to tolerate cisplatin (I,A).median } \\
\text { survival in these patients is about } 14 \text { months, long-term } \\
\text { disease has been reported in about } 15 \% \text { of patients, in } 20.9 \% \\
\text { with lymph-node-only disease compared with only } 6.8 \% \text { with } \\
\text { visceral metastases }\end{array}$ & & NA \\
\hline & $\begin{array}{c}\text { Palliative RT may be used to reduce symptoms such as pain } \\
\text { or bleeding. }\end{array}$ & & \\
\hline
\end{tabular}

Abbreviations: AUA/ASCO/ASTRO/SUO = American Urological Association/American Society of Clinical Oncology/American Society of Radiation Oncology/Society of Urologic Oncology; EAU = European Association of Urology; ESMO = European Society of Medical Oncology; $\mathrm{GC}=$ gemcitabin; $\mathrm{GR}=$ grade of recommendation; $\mathrm{LE}=$ level of evidence; $\mathrm{M}=$ metastasis; $\mathrm{MIBC}=$ muscleinvasive bladder cancer; MVAC = methotrexate, vinblastine, adriamycin, and cisplatin; $\mathrm{N}=$ nodes; NA = not available; NCCN $=$ National Comprehensive Cancer Network; PS = performance status; $\mathrm{pT}=$ pathologic tumor stage; RT = radiotherapy; $\mathrm{T}=$ tumor; TURB $=$ transurethral resection of the bladder.

For none of the cases a significant difference in practice pattern between participants working in an academic versus a nonacademic hospital was observed.

\section{Clinical Cases: Place of Radiotherapy in MIBC in the Adjuvant Setting}

One hundred nineteen (94\%) participants filled in the questions on 'place of RT in the adjuvant setting:' 39 (95\%) urologists, 55 (96\%) radiation oncologists, and 25 (89\%) medical oncologists.

Figure 2 represents the percentages of all participants and per discipline separately considering RT in the adjuvant setting per case.

Again, most differences were found between urologists and radiation oncologists.

For case 1, presenting a patient with MIBC treated with RC and having a microscopically involved surgical margin, 49\% of the urologists would advise against adjuvant RT compared with 20\% and $16 \%$ of the radiation oncologists and medical oncologists, respectively $(P=.001)$.

When patients present with a neo-bladder, the majority of the participants do not consider adjuvant $\mathrm{RT}$ with a rise against $\mathrm{RT}$ of more than $20 \%$ in all groups (case 2: 'no' answered by urologists in $67 \%$ and medical oncologists in $64 \%$ vs. radiation oncologists in $40 \% ; P=.008$ ).

In case of positive pelvic lymph nodes, $65 \%$ of radiation oncologists would consider offering adjuvant RT compared with $41 \%$ and $44 \%$ of the urologists and medical oncologists, respectively $(P=.09)$.

Overall, there were no significant differences in practice between participants working in an academic versus a nonacademic setting, although physicians working in an academic hospital would be less reluctant in offering adjuvant RT in case of the presence of neo-bladder (case 2: 'definitely' answered by participants working in an academic setting in $25 \%$ vs. participants working in a nonacademic setting in $7 \%$; $P=.03)$.

\section{Clinical Cases: Place of Radiotherapy in MIBC in the Metastatic Setting}

Again, 119 (94\%) participants filled in the questions on 'place of RT in the metastatic setting:' 39 (95\%) urologists, 55 (96\%) radiation oncologists, and $25(89 \%)$ medical oncologists.

Figure 3 represents the percentages of all participants and per discipline separately considering RT in the metastatic setting per case.

All radiation oncologists and $96 \%$ of medical oncologists would consider offering palliative RT to patients with painful bone metastases. In contrast, $21 \%$ of urologists would not refer a patient with a painful bone metastasis to the radiation department for palliative RT $(P<.001)$.

Patients with MIBC with pain caused by a lymph node recurrence are still considered to be candidates for palliative RT by $98 \%$ of radiation oncologists compared with $87 \%$ and $84 \%$ of urologists and medical oncologists, respectively $(P<.001)$.

Again, no significant difference in practice was observed for the presented cases in the metastatic setting between participants working in an academic versus a nonacademic hospital.

\section{Results on the Use of Guidelines, Possible Barriers, and Facilitators for Using $R T$ in $M I B C$}

An overview of the answers given by all participants on guidelines, barriers, and facilitators for using RT in MIBC is presented in Table 2.

Clinical decisions for patients with MIBC are most often based on the EAU guidelines. Other sources for decision-making not mentioned in the table are up-to-date textbooks, Erlangen, and AUA guidelines.

Other barriers, in addition to those reported in Table 2, encountered for patient referral to the radiation department are case-dependent $(\mathrm{n}=1)$, patient-specific choice $(\mathrm{n}=1)$, fear of toxicity $(\mathrm{n}=1)$, and no access to clinical trials $(\mathrm{n}=1)$. 


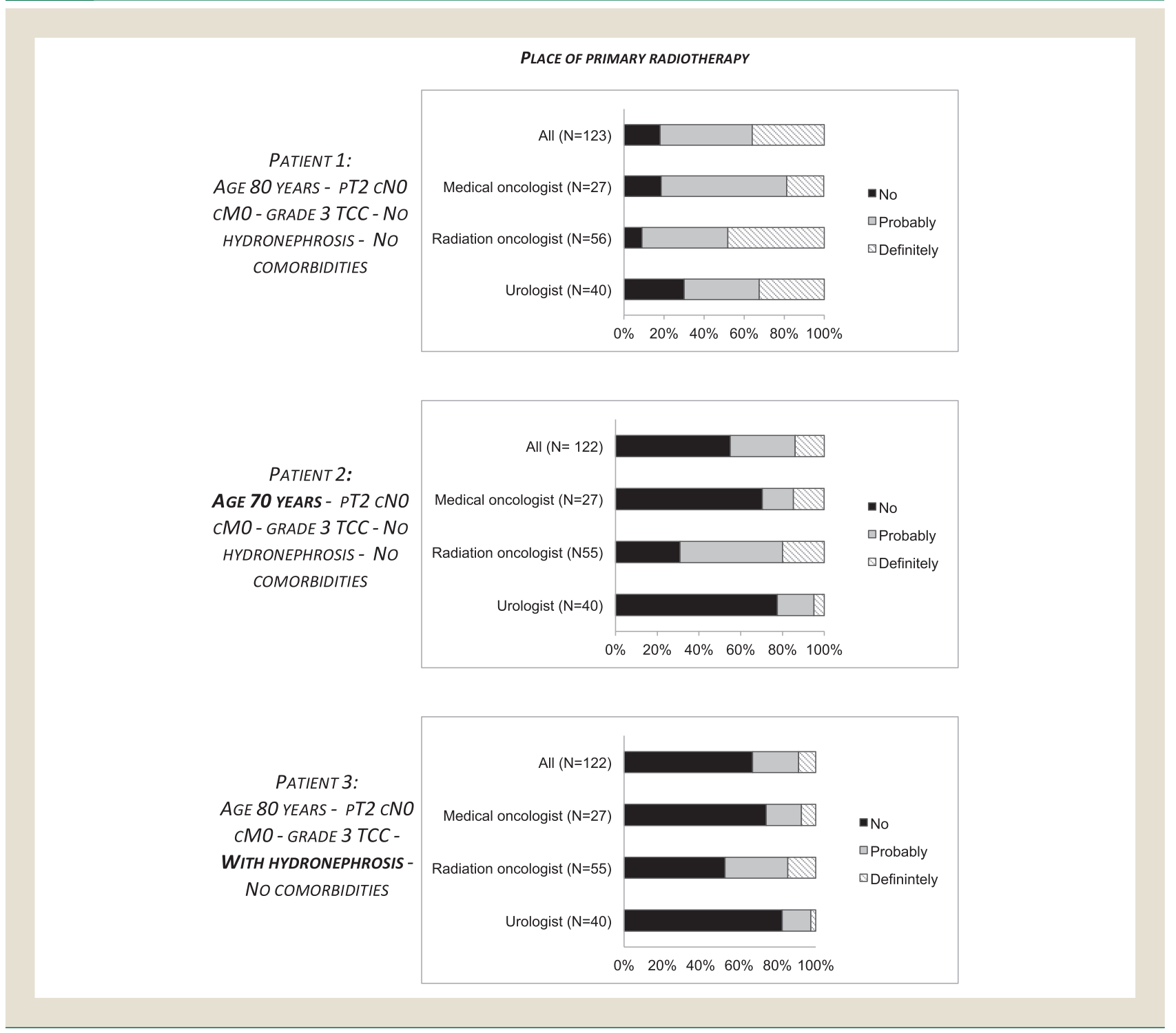

\section{Discussion}

With this Belgian survey, answered by urologists, radiation oncologists, and medical oncologists, we assessed the current place of RT in MIBC. Additional information on use of guidelines and barriers to adhere to guidelines was collected.

Although surgical techniques have improved and Enhanced Recovery After Surgery protocols are gradually implemented, morbidity after radical cystectomy remains substantial. ${ }^{11,12} \mathrm{Mul}-$ timodality bladder-sparing therapy (BST), consisting of chemoradiation after (maximal) transurethral resection of the bladder (TURB) is an alternative for surgery. Until now, there has been no direct comparison between both treatment options. One randomized trial was prematurely closed owing to poor patient accrual. ${ }^{13}$ Nevertheless, similar survival outcomes between both treatment strategies have been reported recently. ${ }^{14}$ Other prospective trials have confirmed long-term disease control with intact bladder with BST. ${ }^{15-17}$ Based on these publications, international guidelines confirm that BST can be offered to highly selected patients as an alternative for RC (Table 1). Ideal candidates for BST are patients with T2 disease and complete removal after TURB. ${ }^{18,19}$

Our survey revealed that age was an important factor in the decision-making whether or not to offer BST for a patient with T2 disease. Neither the EAU, NCCN, ESMO, nor the AUA/ASCO/ ASTRO/SUO guidelines, however, indicate that younger age is a contraindication for BST. ${ }^{7-10}$ In a systematic review, both overall and cancer-specific survival as well as perioperative mortality worsened with increasing age when $\mathrm{RC}$ was the treatment of choice. Worse outcome in octogenarians was suggested to be the result of a suboptimal radical treatment. ${ }^{20,21}$ In this older population, BST is an excellent alternative for less aggressive and consequently noncurative surgery. This is confirmed by a recently published registry- 


\section{The Current Place of Radiotherapy in Muscle Invasive Bladder Cancer}

\section{Figure 2 Representation of the Percentages of All Participants and per Discipline Separately Considering Radiotherapy in the Adjuvant Setting per Case}

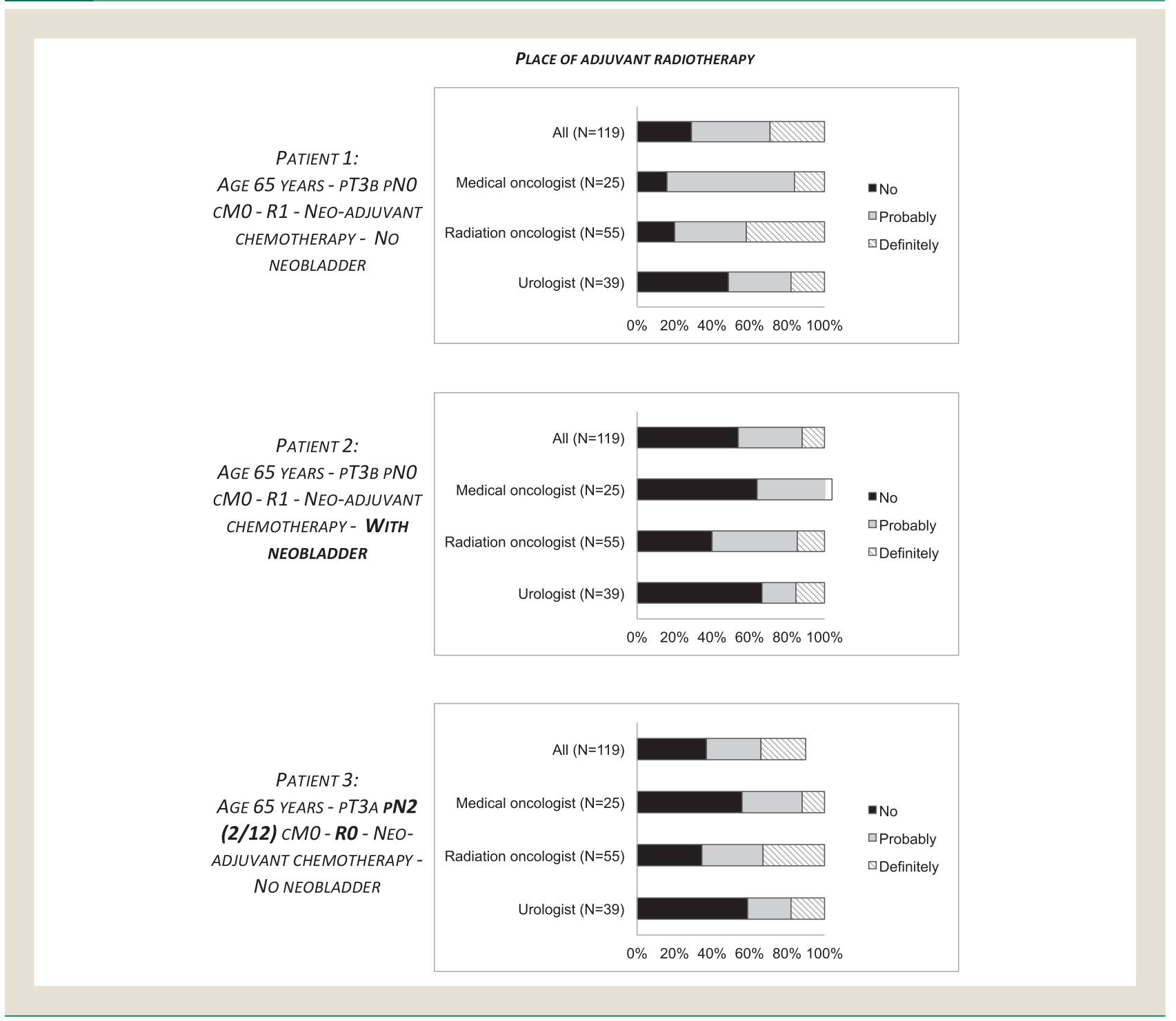

based analysis in which similar survival after surgery and BST was observed in patients aged $\geq 80$ years. $^{22}$

In addition to younger age, the presence of hydronephrosis was seen as a contraindication for BST based on the low number of participants considering BST in an 80-year old patient with a T2 MIBC and hydronephrosis. Tumor-associated hydronephrosis is indeed associated with low rates of complete response and consequently low rates of bladder preservation. Therefore, hydronephrosis is seen as a contra-indication for BST (Table 1). ${ }^{15,19}$

A recent small retrospective analysis performed by Chiang et al evaluated the pattern of failure in patients with MIBC, treated with a BST, who had unfavorable characteristics such as hydronephrosis. Higher rates of distant metastases and worse survival were observed in these patients, although the bladder preservation was not inferior when compared with patients without hydronephrosis. ${ }^{23}$ For patients who refuse or are deemed unsuitable for an RC, a BST should thus not be denied even in the presence of tumor-associated hydronephrosis.

Despite aggressive surgery, the outcome after RC remains poor with 5-year overall survival rates of only $50 \%{ }^{24}$ Ultimately, $30 \%$ of the patients with $\geq$ pT3 tumors develop a pelvic recurrence. ${ }^{25-27}$ Local recurrences are often debilitating and painful and cause morbidity (lymphedema and venous thrombosis). It has also been suggested that occurrence of local and lymph node recurrence is linked to the development of distant metastasis. ${ }^{28}$ Significant improvement in local-regional recurrence and a marginally significant improvement in disease-free survival are observed with adjuvant $\mathrm{RT}^{29}$ but severe toxicity hampered enthusiasm for implementing adjuvant RT after RC in daily practice. ${ }^{30}$ Technological advancements in RT planning and positioning have resulted in better coverage of the target volume while sparing more normal tissue (mainly small bowel), as well as in a more precise delivery of 
Figure 3 Representation of the Percentages of All Participants and per Discipline Separately Considering Radiotherapy in the Metastatic Setting per Case

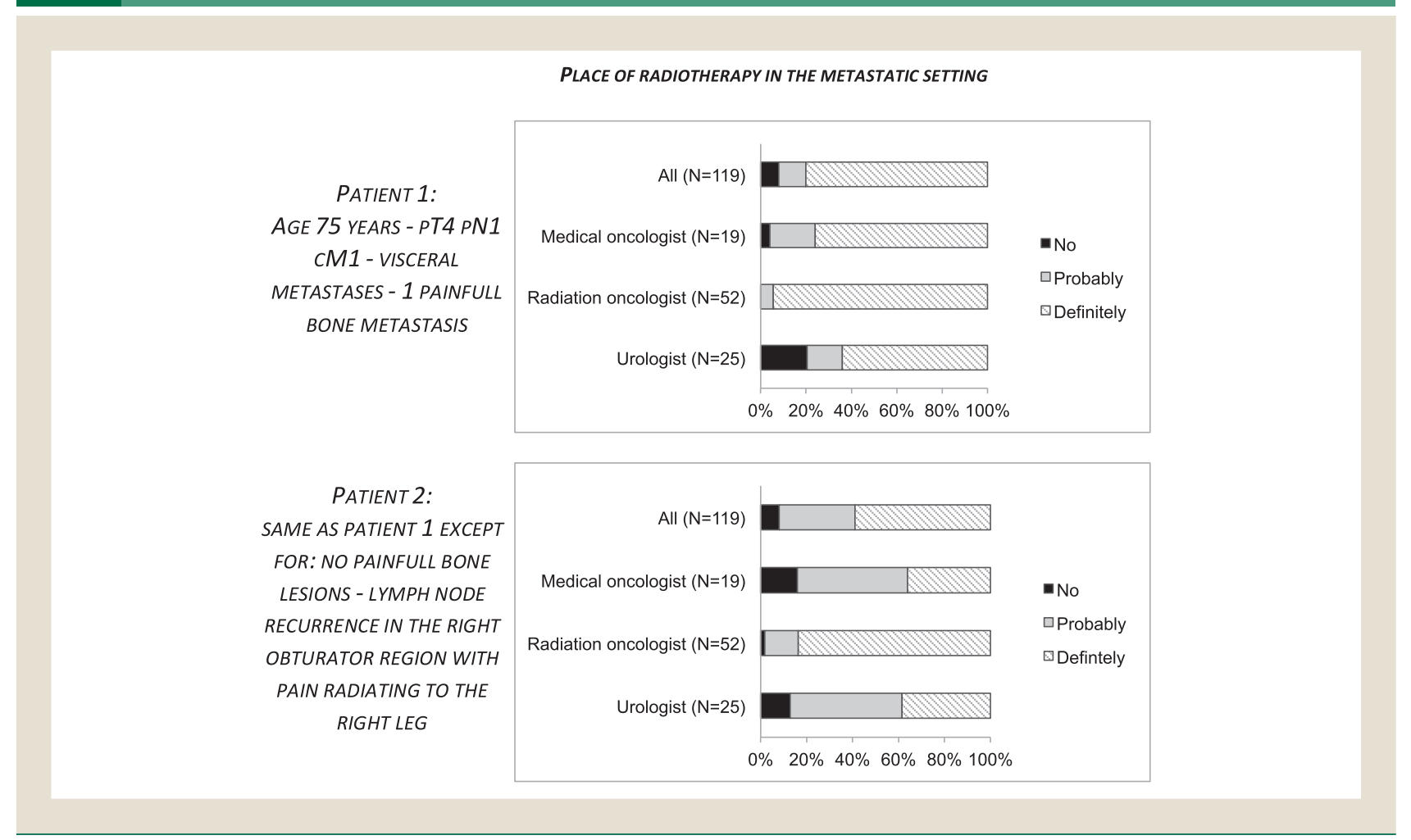

the RT. ${ }^{31-33}$ Therefore, the use of adjuvant RT in properly selected patients with MIBC is reconsidered in different ongoing prospective studies. ${ }^{34}$

Risk factors for locoregional relapse after RC have been identified and include: $\geq$ pT3 stage and positive margins or $<10$ lymph nodes removed. ${ }^{34,35}$ Additional analysis is required to define the impact of node positivity on locoregional failure. ${ }^{34}$ Interestingly, although both the $\mathrm{EAU}^{7}$ and $\mathrm{NCCN}^{8}$ guidelines consider adjuvant RT as an alternative for adjuvant chemotherapy in patients with locally advanced MIBC (including node-positive patients), > 50\% of the responding Belgian urologists do not consider adjuvant RT in any of the cases. For the majority of radiation oncologists and medical oncologists, the presence of a positive surgical margin was a reason for referral for adjuvant RT, whereas, surprisingly, the presence of positive lymph nodes was not. The presence of a neobladder hampered the motivation to refer a patient for adjuvant RT. Nevertheless the use of moderate-dose adjuvant RT after radical cystectomy with orthotopic neo-bladder reconstruction was proven to be feasible and safe in this setting. ${ }^{36}$

The important role of RT in the treatment of painful bone metastases is well established irrespective of the primary tumor. Single fraction RT is nowadays standard of care for symptomatic and uncomplicated bone metastases. ${ }^{37}$ Our survey confirmed that $\mathrm{RT}$ is a well-recognized palliative treatment. In case of a pelvic recurrence only, it has been suggested that the role of RT might exceed a sole palliative one for pain relief. For patients with local or lymph node recurrence, the prognosis is reserved with a median survival of 4 months. ${ }^{38}$ If patients with isolated local or lymph node recurrence are treated with external beam RT, 1-year survival significantly improves from $2 \%$ (no RT) to $27 \% .{ }^{37}$

Previous work identified the following barriers to physicians' adherence to clinical practice guidelines: knowledge (lack of awareness or lack of familiarity), attitudes (lack of agreement, lack of self-efficacy, lack of outcome expectancy), or behavior (external barriers). ${ }^{39}$ According to our survey, external barriers such as absence of referral, lack of or negative experience with RT, and no belief in a positive effect of RT in MIBC were among the most commonly reported barriers for adherence to guidelines.

Another study by Pathman et al investigated an awareness-toadherence model of the steps to clinical guideline compliance. ${ }^{40}$ They found that the first important step in the adherence to clinical guidelines was the awareness of the guidelines. ${ }^{40}$ In our survey, $12 \%$ of the participants answered that they were not aware of existing guidelines.

The next steps are agreement with the guidelines and, thereafter, adopting the guidelines and adhering to them at appropriate times. ${ }^{40}$ In current international guidelines, recommendations on $\mathrm{RT}$ in MIBC are most often limited as being an alternative for other therapies such as RC in the primary setting and chemotherapy in the adjuvant and metastatic setting. This dubiety makes adherence to guidelines difficult. The majority of the participants answered 'probably' on most questions on primary and adjuvant RT. This reflects well the low grade of recommendations in the EAU, NCCN, ESMO, and AUA/ASCO/ASTRO/SUO guidelines. ${ }^{7-10}$ Nevertheless, according to our survey, providing a summary of 


\section{The Current Place of Radiotherapy in Muscle Invasive Bladder Cancer}

Table 2 Overview of the Answers Given by All Participants on Guidelines, Barriers, and Facilitators for Using Radiotherapy in MIBC

Use of Guidelines: Possible Barriers and Facilitators for Using Radiotherapy in MIBC

\begin{tabular}{l|c}
\hline & $\begin{array}{c}\text { All } \\
\text { Participants } \\
\text { (N = 119), } \\
\text { N (\%) }\end{array}$ \\
\hline $\begin{array}{l}\text { Which guidelines do you follow in your practice? Multiple } \\
\text { answers possible. }\end{array}$ & 81 (68) \\
\hline EAU guidelines & $43(36)$ \\
\hline Institutional guidelines & $42(35)$ \\
\hline ESMO guidelines & $40(34)$ \\
\hline NCCN guidelines & $14(12)$ \\
\hline National guidelines & $6(5)$ \\
\hline $\begin{array}{l}\text { Other } \\
\text { I do not follow guidelines }\end{array}$ & $3(3)$ \\
\hline $\begin{array}{l}\text { Which would be possible barriers for you to apply guidelines } \\
\text { for radiotherapy on MIBC? Multiple answers possible. }\end{array}$ & \\
\hline None relevant: I always follow & $44(37)$ \\
\hline $\begin{array}{l}\text { External barriers: no referral, difficult access, cost, health } \\
\text { economics... }\end{array}$ & $21(18)$ \\
\hline I have no experience with radiotherapy in MIBC & 17 (14) \\
\hline I'm not aware of existing guidelines & $14(12)$ \\
\hline Other & $14(12)$ \\
\hline I have negative experience with radiotherapy in previous \\
practice
\end{tabular}

Abbreviations: EAU = European Association of Urology; ESMO = European Society of Medical Oncology; $\mathrm{MBC}=$ muscle-invasive bladder cancer; $\mathrm{NCCN}=$ National Comprehensive Cancer Network.

available guidelines is regarded as being effective in increasing the awareness of potential role of RT in MIBC.

There are some limitations in this survey-based paper. At first, offering participants the possibility to answer 'probably' might be regarded as a weakness of the current survey. Another important limitation of our study is the low response rate, which is influenced by several factors. Survey fatigue will undoubtedly have negatively influenced the number of participants. Also, our survey was send to all Belgian urologists, radiation oncologists, and medical oncologists regardless of their subspecialization in urology or oncology practice. Limited experience with treating patients with MIBC might therefore have contributed to the low response rate. The response rate of our study is, however, in line with other surveys. ${ }^{41-44}$ In the survey performed by Walker et al, the place of perioperative chemotherapy for bladder cancer was explored. ${ }^{44}$ The response rate for urologists, medical oncologists, and radiation oncologists was $20 \%, 36 \%$, and $31 \%$, respectively. ${ }^{44}$ When only including those physicians who treated $>10$ patients with MIBC per year, the response rate increases to $34 \%, 47 \%$, and $28 \%$ for urologists, medical oncologists, and radiation oncologists, respectively. ${ }^{44}$ Given the low response rate, our findings should be interpreted with caution as they might not be representative for all Belgian urologists, radiation oncologists, and medical oncologists as a whole.

Third, this survey was limited to Belgian physicians. The results might therefore not be extrapolated to other countries. The answers on the clinical cases are in line with the important underutilization observed in the analysis conjointly performed by the Belgian College for Physicians in Radiation Oncology and the Belgian Cancer Registry. ${ }^{4}$ The more granular data in this survey, moreover, show that the underutilization applies to RT in all stages of MIBC, even, although to a lesser extent, in the palliative setting. Whether the lack of promoting RT in this setting (when compared to systemic treatments, for example) is a major cause of this underusage is a contemporary hot debate.

\section{Conclusion}

There is a lot of controversy regarding the place of RT in MIBC, with a clear variation between oncology professionals and a dependence of tumor-and patient-related factors. Barriers and facilitators to use RT for MIBC were identified and should be addressed, keeping in mind the actual gap in RT utilization and predicted increase in patients requiring RT for MIBC in the future.

\section{Clinical Practice Points}

- In international guidelines, RT is recognized to be a treatment option for patients with bladder cancer in the primary, adjuvant, and palliative settings. However, it actually has been suggested that there is a gap between optimal and actual use of RT in MIBC.

- Our survey, conducted among radiation oncologists, medical oncologists, and urologists, confirms the underusage and differences in use of RT in the primary and adjuvant setting between radiation oncologists, medical oncologists, and urologists despite international recommendations. In the palliative setting, these discrepancies are less pronounced.

- Barriers and facilitators to use RT should be recognized and addressed. Awareness of the place of RT must be increased seeing the gap in RT utilization and predicted increase in patients requiring RT for MIBC.

\section{Acknowledgments}

The authors would like to thank the Belgian Association of Urology, Belgian College for Physicians in Radiation Oncology, and Belgian Society of Medical Oncologists.

This work is funded by a grant of Kom op tegen Kanker (Stand up to Cancer), the Flemish cancer society (ref: 0010091). The granting body was not involved in data collection or analysis. 


\section{Disclosure}

The authors have stated that they have no conflicts of interest.

\section{Supplemental Data}

Supplemental tables accompanying this article can be found in the online version at https://doi.org/10.1016/j.clgc.2018.07.026.

\section{References}

1. Leow J, William M, Rajagopal P, et al. Adjuvant chemotherapy for invasive bladder cancer: a 2013 updated systematic review and meta-analysis of randomized trials. Eur Urol 2014; 66:42-54.

2. Borras JM, Barton M, Grau C, et al. The impact of cancer incidence and stage on optimal utilization of radiotherapy: methodology of a population based analysis by the ESTRO-HERO project. Radiot Oncol 2015; 116:45-50.

3. Borras JM, Lievens Y, Barton M, et al. How many new cancer patients in Europe will require radiotherapy by 2025? An ESTRO-HERO analysis. Radiot Oncol 2016; 119:5-11.

4. Lievens Y, De Schutter H, Stellamans K, Rosskamp M, Van Eycken L, on behalf of the Belgian College for Physicians in Radiation Oncology. Radiotherapy access in Belgium: how far are we from evidence-based utilisation. EJC 2017; 84:102-13.

5. Borras JM, Lievens Y, Dunscombe P, et al. The optimal utilization proportion of external beam radiotherapy in European countries: an ESTRO-HERO analysis. Radiot Oncol 2015; 116:38-44.

6. Haines A, Kuruvilla S, Borchert M. Bridging the implementation gap between knowledge and action for health. Bull World Health Organ 2004; 82:724-31.

7. Witjes JA, Lebret T, Compérat EM, et al. Updated 2016 EAU guidelines on muscle-invasive and metastatic bladder cancer. Eur Urol 2017; 71:462-75.

8. Spiess PE, Aqarwal N, Bangs R, et al. Bladder cancer, version 5.2107, NCCN clinical practice guidelines in oncology. J Natl Compr Can Netw 2017; 15:1240-67.

9. Bellmunt J, Orsola A, Leow JJ, et al. Bladder cancer: ESMO practice guidelines for diagnosis, treatment and follow up. Ann Oncol 2014; 25:40-8.

10. Chang SS, Bochner BH, Chou, et al. Treatment of non-metastatic muscle-invasive bladder cancer: AUA/ASCO/ASTRO/SUO Guideline. J Urol 2017; 198:552-9.

11. Bazargani ST, Djaladat $\mathrm{H}$, Ahmadi $\mathrm{H}$, et al. Gastro-intestinal complications following radical cystectomy using enhanced recovery protocol. Eur Urol Focus 2017. https://doi.org/10.1016/j.euf.2017.04.003.

12. Lauridsen SV, Tonnesen H, Jensen BT, Neuner B, Thind P, Thomsen T. Complications and health-related quality of life after robot-assisted versus open radical cystectomy: a systematic review and meta-analysis of four RCTs. Syst Rev 2017; 6:150.

13. Huddart RA, Birtle A, Maynard L, et al. Clinical and patient-reported outcomes of SPARE - a randomised feasibility study of the selective bladder preservation versus radical cystectomy. BJU 2017; 120:639-50.

14. Kulkarni GS, Hermanns T, Wei Y, et al. Propensity score analysis of radical cystectomy versus bladder-sparing trimodal therapy in the setting of a multidisciplinary bladder cancer clinic. J Clin Oncol 2017; 35:2299-305.

15. Efsthathiou JA, Spiegel DY, Shipley WU, et al. Long-term outcomes of selective bladder preservation by combined-modality therapy for invasive bladder cancer: the MGH experience. Eur Urol 2012; 61:705-11.

16. James ND, Hussain SA, Hall E, et al. Radiotherapy with or without chemotherapy in muscle invasive bladder cancer. N Engl J Med 2012; 366:1477-88.

17. Caffo O, Thompson C, De Santis M, et al. Concurrent gemcitabine and radiotherapy for the treatment of muscle-inviasve bladder cancer: a pooled individual data analysis of eight phase I-II trials. Radiot Oncol 2016; 121:193-8.

18. Chung PW, Bristow RG, Milosevic MF, et al. Long-term outcome of radiation-based conservation therapy for invasive bladder cancer. Urol Oncol 2007; 25:303e9.

19. Ploussard G, Daneshmand S, Efstathiou JA, et al. Critical analysis of bladder sparing with trimodal therapy in muscle-invasive bladder cancer: a systematic review. Eur Urol 2017; 66:120-37.

20. Fonteyne V, Ost P, Bellmunt J, et al. Curative treatment for muscle invasive bladder cancer in elderly patients: a systematic review. Eur Urol 2018; 73:40-50.

21. Bream MJ, Maurice MJ, Altschuler J, Zhu H, Abouassaly R. Increased use of cystectomy in patients 75 and older: a contemporary analysis of survival and perioperative outcomes from the national cancer database. Urology 2017; 100:72-8.

22. Fisher-Valuck BW, Rao YJ, Rudra S, et al. Treatment patterns and overall survival outcomes of octogenarians with muscle invasive cancer of the bladder: an analysis of the national cancer database. J Urol 2018; 199:416-23.
23. Chiang Y, Cheng JC, Huang CY, et al. A role of multimodality bladder-preserving therapy in patients with muscle-invasive bladder cancer plus hydronephrosis with or without pelvic nodal involvement. J Formos Med Assoc 2017; 116:689-96.

24. Grossman HB, Natale RB, Tangen CM, et al. Neoadjuvant chemotherapy plus cystectomy compared with cystectomy alone for locally advanced bladder cancer. N Engl J Med 2003; 349:859-66.

25. Baumann BC, Guzzo T, He J, et al. Bladder cancer patterns of pelvic failure: implications for adjuvant radiation therapy. Int J Radiat Oncol Biol Phys 2013; 85: 363-9.

26. Herr HW, Faulkner JR, Grossman HB, et al. Surgical factors influence bladder cancer outcomes: a cooperative group report. J Clin Oncol 2004; 22:2781-9.

27. Christodouleas JP, Baumann BC, He J, et al. Optimizing bladder cancer locoregional failure risk stratification after radical cystectomy using SWOG 8710. Cancer 2014; 120:1272-80.

28. Pollack A, Zagars GK, Dinney CP, et al. Preoperative radiotherapy for muscleinvasive bladder carcinoma. Long term follow up and prognostic factors for 338 patients. Cancer 1994; 74:2819-27.

29. Zaghloul MS, Christodouleas JP, Smith A, et al. Adjuvant chemotherapy plus radiotherapy vs adjuvant chemotherapy alone for locally advanced bladder cancer after radical cystectomy: a randomized phase 2 trial. JAMA Surg 2018; 153: e174591.

30. Zaghloul MS, Awwad HK, Omar S, et al. Postoperative radiotherapy of carcinoma in bilharzial bladder. Improved disease-free survival through improving local control. Int J Radiat Oncol Biol Phys 1992; 22:511-7.

31. Wang-Chesebro A, Xia P, Coleman J, et al. Intensity-modulated radiotherapy improves lymph node coverage and dose to critical structures compared with threedimensional conformal radiation therapy in clinically localized prostate cancer. Int I Radiat Oncol Biol Phys 2006; 66:654-62.

32. Fonteyne V, Lumen N, Ost P, et al. Hypofractionated intensity-modulated arc therapy for lymph node metastasized prostate cancer: toxicity and 3-years clinical outcome. Radiother Oncol 2013; 109:229-34.

33. Vandecasteele K, De Neve W, De Gersem W, et al. Intensity-modulated arc therapy with simultaneous integrated boost in the treatment of primary irresectable cervical cancer. Treatment planning, quality control, and clinical implementation. Strablenther Onkol 2009; 185:799-807.

34. Bauman BC, Sargos P, Eapen LJ, et al. The rationale for post-operative radiation in localized bladder cancer. Bladder Cancer 2017; 3:19-30.

35. Reddy AV, Pariser JJ, Pearce SM, et al. Patterns of failure after radical cystectomy for pT3-4 bladder cancer: implications for adjuvant radiation therapy. Int J Radiat Oncol Biol Phys 2016; 94:1031-9.

36. Ballas L, Sargos P, Orré M, Bian SX, Daneshmand S, Eapen LJ. Tolerance of orthotopic ileal neobladders to radiotherapy: a multi-institutional retrospective study. Clin Genitourin Cancer 2017; 15:711-6.

37. Wu JS, Wong RK, Lloyd NS, Johnston M, Bezjak A, Whelan T. Supportive Care Guidelines Group of Cancer Care Ontario. Radiotherapy fractionation for the palliation of uncomplicated painful bone metastases - an evidence-based practice guideline. BMC Cancer 2004; 4:71.

38. Ploeg M, Kums AC, Aben KK, et al. Prognostic factors for survival in patients with recurrence of muscle invasive bladder cancer after treatment with curative intent. Clin Genitourin Cancer 2011; 9:14-21.

39. Cabana MD, Rand CS, Powe NR, et al. Why don't physicians follow clinical practice guidelines? A framework for improvement. JAMA 1999; 282:1458-65.

40. Pathman DE, Konrad TR, Freed GL, Freeman VA, Koch GG. The awareness-to-adherence model of the steps to clinical guideline compliance: the case of pediatric vaccine recommendations. Med Care 1996; 34 873-89.

41. Farell MJ, Yahya JB, Degnin C, et al. Timing of thoracic radiation therapy with chemotherapy in limited-stage small cell lung cancer: survey of US radiation oncologists on current practice patterns. Clin Lung Cancer 2018. https://doi.org/ 10.1016/j.clic.2018.04.007.

42. Yoo HJ, Hong JJ, Bok Ko Y, et al. Current Practice of cytoreductive surgery and hyperthermic intraperitoneal chemotherapy in the treatment of peritoneal surface maligniancies: an international survey of oncologic surgeons. World J Surg Oncol 2018; 16:92.

43. Melnychuck M, Vindrola-Padros C, Aitchison M, et al. Centralising specialists cancer surgery services in England: survey of factors that matter to patients and carers of health professionals. BMC Cancer 2018; 18:226.

44. Walker M, Doiron RC, French S, et al. Peri-operative chemotherapy for bladder cancer: a survey of providers to determine barriers and enablers. Bladder Cancer 2018; 4:49-65. 


\section{The Current Place of Radiotherapy in Muscle Invasive Bladder Cancer}

\section{Supplemental Table 1 Overview of Questions Asked to the Participants of the Survey}

Demographic Characteristics

Please specify the type of hospital you practice in

Please specify your general clinical experience

Please specify your speciality

Place of radiotherapy in the primary setting

Would you consider (chemo)radiotherapy as an alternative for radical cystectomy in MIBC as a bladder-sparing treatment in following cases?

Patient 1: Age 80 years - pT2 cNO cMO - grade 3 TCC - No hydronephrosis - No comorbidities

Patient 2: Same as patients 1 except for: Age 70 years

Patient 3: Same as patient 1 except for: Hydronephrosis

Place of radiotherapy in the adjuvant setting

Would you consider radiotehrapy as an adjuvant treatment after radical cystectomy for MIBC in following cases?

Patient 1: Age 65 years - pT3b pNO cM0 - R1 - Neo-adjuvant chemotherapy - No neobladder

Patient 2: Same as patient 1 except for: With neobladder

Patient 3: Same as patient 1 except for: Tumor stage pT3a pN2 (2/12) CMO - RO

Place of radiotherapy in the metastatic setting

Would you consider radiotherapy as a palliative treatment for metastatic MIBC in following cases?

Patient 1: Age 75 years - pT4 pN1 cM1 - visceral metastases - 1 painful bone metastasis

Patient 2: Same as patient 1 except for: no painfull bone lesions - lymph node recurrence in the right obturator region with pain radiating to the right leg

Guidelines on MIBC

Which guidelines do you follow in your practice? Multiple answers possible.
Academic hospital

Non academic hospital

$<5$ years

between 5 and 10 years

$>10$ years

I have no experience

Urologist

Radiation Oncologist

Medical Oncologist

No

Probably

Definitely

No

Probably

Definitely

No

Probably

Definitely

No

Probably

Definitely

No

Probably

Definitely

No

Probably

Definitely

No

Probably

Definitely

No

Probably

Definitely

EAU guidelines

ESMO guidelines

NCCN guidelines

National guidelines 


\begin{tabular}{|c|c|}
\hline & Institutional guidelines \\
\hline & I do not follow guidelines \\
\hline & Other \\
\hline \multirow{8}{*}{$\begin{array}{l}\text { Which would be possible barriers for you to apply guidelines for radiotherapy } \\
\text { on MIBC? Multiple answers possible. }\end{array}$} & I'm not aware of existinig guidelines \\
\hline & I have no experience with radiotherapy in MIBC \\
\hline & I have negative experience with radiotherapy in previous practice \\
\hline & I do not agree with guidelines \\
\hline & I do not believe that radiotherapy will improve the outcome of a patient with MIBC \\
\hline & External barriers: no referral, difficult access, cost, health economics... \\
\hline & None relevant: I always follow \\
\hline & Other \\
\hline \multirow{7}{*}{$\begin{array}{l}\text { What in your opinion would improve the awareness of existing guidelines on } \\
\text { the use of radiotherapy in MIBC? Multiple answers possible. }\end{array}$} & Compact summary of guidelines on the website of the national organistaion \\
\hline & Latest update of existing guidelines by e-mail \\
\hline & Short overview of current trials by e-mail \\
\hline & Dissemination through symposia \\
\hline & Multidisciplinary oncological consultation \\
\hline & No need for improvement \\
\hline & Other \\
\hline
\end{tabular}

Abbreviations: EAU = European Association of Urology; ESMO = European Society of Medical Oncology; MIBC = muscle-invasive bladder cancer; NCCN = National Comprehensive Cancer Network. 